\title{
Triptolide induces $S$ phase arrest via the inhibition of cyclin $E$ and CDC25A and triggers apoptosis via caspase- and mitochondrial- dependent signaling pathways in A375.S2 human melanoma cells
}

\author{
FANG-MING HUNG $^{1 *}$, YUNG-LIANG CHEN ${ }^{2 *}$, AN-CHENG HUANG $^{3}$, YU-PING HSIAO ${ }^{4,5}$, JAI-SING YANG ${ }^{6}$, \\ MING-TENG CHUNG ${ }^{7}$, FU-SHIN CHUEH ${ }^{8}$, HSU-FENG LU ${ }^{9,10}$ and JING-GUNG CHUNG ${ }^{11,12}$ \\ ${ }^{1}$ Department of Surgical Intensive Care Unit, Far Eastern Memorial Hospital, Taipei; \\ ${ }^{2}$ Department of Medical Laboratory Science and Biotechnology, Yuanpei University, Hsinchu; ${ }^{3}$ Department of Nursing, \\ St. Mary's Medicine Nursing and Management College, Yilan; ${ }^{4}$ Institute of Medicine, School of Medicine, \\ Chung Shan Medical University, Taichung; ${ }^{5}$ Department of Dermatology, Chung Shan Medical University Hospital, \\ Taichung; ${ }^{6}$ Department of Pharmacology, China Medical University, Taichung; ${ }^{7}$ Department of Anatomical Pathology, \\ Cheng Hsin General Hospital, Taipei; ${ }^{8}$ Department of Health and Nutrition Biotechnology, Asia University, Taichung; \\ ${ }^{9}$ Department of Clinical Pathology, Cheng Hsin General Hospital, Taipei; ${ }^{10}$ Department of Restaurant, Hotel and \\ Institutional Management, Fu-Jen Catholic University, Taipei; ${ }^{11}$ Department of Biological Science and Technology, \\ China Medical University, Taichung; ${ }^{12}$ Department of Biotechnology, Asia University, Taichung, Taiwan, R.O.C.
}

Received October 25, 2012; Accepted December 17, 2012

DOI: 10.3892/or.2013.2230

\begin{abstract}
Triptolide (TPL), a diterpene triepoxide compound, extracted from Tripterygium wilfordii Hook F. [a traditional Chinese medicinal herb (TCM)], has demonstrated great chemotherapeutic potential for the treatment of tumors. However, the anticancer mechanisms of action of TPL in human skin cancer remain to be further investigated. In this study, we used A375.S2 human melanoma skin cancer cells as a model to investigate the effect of TPL on cell death. A375.S2 cells were treated with various concentrations of TPL for different periods of time and investigated the effects on cell cycle distribution and apoptosis were investigated. The data showed that TPL induced cell morphological changes, decreased the percentage of viable cells, and induced S phase arrest and apoptosis in A375.S2 cells in a concentration- and time-dependent manner. Furthermore, we used flow cytometry analysis and the data showed that TPL promoted reactive oxygen species, NO and
\end{abstract}

Correspondence to: Professor Jing-Gung Chung, Department of Biological Science and Technology, China Medical University, 91 Hsueh-Shih Road, Taichung 40402, Taiwan, R.O.C.

E-mail: jgchung@mail.cmu.edu.tw

Dr Hsu-Feng Lu, Department of Clinical Pathology, Cheng Hsin General Hospital, 45 Cheng Hsin St., Taipei 112, Taiwan, R.O.C.

E-mail: ch1835@chgh.org.tw

*Contributed equally

Key words: triptolide, apoptosis, $\mathrm{S}$ phase arrest, mitochondrialmediated pathway, A375.S2 cells
$\mathrm{Ca}^{2+}$ production, decreased the mitochondrial membrane potential $\left(\Delta \Psi_{m}\right)$ and increased the activity of caspase-3, -8 and -9 in the A375.S2 cells. Western blot analysis showed that TPL promoted the expression of p21 and p27 but inhibited that of cyclin A and CDC25A, leading to S phase arrest. Furthermore, the data also showed that TPL promoted the expression of Fas and FasL and increased the activity of caspase-3, -8 and -9 , cytochrome $c$, Bax, apoptosis-inducing factor (AIF) and endonuclease $\mathrm{G}$ (Endo $\mathrm{G}$ ); however, the expression of Bax was decreased, leading to apoptosis. Based on these observations, TPL induces apoptosis in A375.S2 cells through Fas-, caspaseand mitochondrial-mediated pathways.

\section{Introduction}

Skin cancer is one of the main causes of cancer-related mortality worldwide and cutaneous melanoma is one of the most aggressive forms of skin cancer in humans $(1,2)$. Although melanoma accounts for approximately $4 \%$ of all dermatological cancers, $>80 \%$ of deaths from skin cancer are associated with melanoma. Furthermore, the ten-year survival rate for patients with metastatic melanoma is $<10 \%(3,4)$. The cure rate for patients with melanoma has not achieved clinically satisfactory response rates. Therefore, several studies have focused on the discovery of novel therapeutic agents derived form natural products for cancer prevention and therapy. The induction of tumor cell apoptosis is one of the pursued strategies in chemotherapy $(5,6)$. In particular, molecules associated with the regulation of apoptosis are clinically relevant targets for chemical intervention $(7,8)$.

Triptolide (TPL), a diterpenoid triepoxide, derived from the herb Tripterygium wilfordii, has been used as a herbal medicine in China for hundreds of years $(9,10)$. TPL has been shown to 
induce apoptosis in a number of cancer cells, such as breast $(11,12)$, lung $(13)$, pancreatic $(14,15)$ and colon cancer $(16,17)$. It has been reported that TPL-induced apoptosis is associated with the death receptor and mitochondrial-mediated pathways in leukemic (18-20) and pancreatic cancer cells $(14,15)$. Recently, it was reported that TPL induced the apoptosis of pancreatic cancer cells via the downregulation of decoy receptor 3 (DcR3) expression (15). TPL has been shown to inhibit colon cancer cell proliferation by the induction of G1 phase arrest through the upregulation of p21 (17). In our laboratory, we found that TPL induced the apoptosis of NCI-H295 human adrenal cancer cells through a mitochondrial-dependent pathway (21).

In the present study, A375.S2 human melanoma cells were employed as a cell model to evaluate the in vitro antimelanoma potential of TPL. We found that the cytotoxic effect of TPL on A375.S2 cell growth was associated with cell cycle arrest at the $\mathrm{S}$ phase and the induction of apoptosis through the caspase- and mitochondrial-dependent signaling pathways. The underlying molecular mechanisms leading to these profound effects were also investigated.

\section{Materials and methods}

Chemicals and reagents. TPL, dimethyl sulfoxide (DMSO), RNase A, Triton X-100 and propidium iodide (PI) were purchased from Sigma Chemical Co. (St. Louis, MO, USA). Minimum essential medium (MEM), fetal bovine serum (FBS), L-glutamine penicillin-streptomycin and trypsinEDTA were purchased from Gibco/Invitrogen (Carlsbad, CA, USA). The Annexin V-FITC apoptosis detection kit was from Gibco/Invitrogen. 2,7-Dichlorodihydrofluorescein diacetate (DCFH-DA) for determination of reactive oxygen species (ROS) levels, $\mathrm{DiOC}_{6}$ for determination of mitochondrial membrane potential $(\Delta \Psi m)$ and Fluo-3/AM for determination of intracellular $\mathrm{Ca}^{2+}$ levels were purchased from Oncoimmunin, Inc. (Gaithersburg, MD, USA).

Cell culture. The A375.S2 human malignant melanoma cell line was purchased from the Food Industry Research and Development Institute (Hsinchu, Taiwan). The A275.S2 cells were cultured in $75 \mathrm{~cm}^{2}$ tissue culture flasks with MEM supplemented with 10\% FBS (Gibco-BRL, Gaithersburg, MD, USA), penicillin-streptomycin (100 U/ml penicillin and $100 \mu \mathrm{g} / \mathrm{ml}$ streptomycin) and $2 \mathrm{mM} \mathrm{L}$-glutamine and grown in a humidified atmosphere of air containing $5 \% \mathrm{CO}_{2}$ at $37^{\circ} \mathrm{C}$ as previously described $(22,23)$.

Cell morphological changes examinations, viability and cell cycle distribution assays. The A375.S2 cells $\left(2 \times 10^{5}\right.$ cells/ well) were maintain in 12 -well plates and incubated at $37^{\circ} \mathrm{C}$ for $24 \mathrm{~h}$ before being treated with $0,15,20,25,30$ and $35 \mathrm{nM}$ of TPL for 24 and $48 \mathrm{~h}$. DMSO (solvent; $0.5 \%$ ) was used for the control regimen. Cells were observed and photographed under a contrast phase microscope at $\mathrm{x} 400$ magnification for the determination of morphological changes. Cells were harvested by centrifugation at $1,000 \mathrm{x} \mathrm{g}$ for $5 \mathrm{~min}$ and the cell pellets were then dissolved with $0.5 \mathrm{ml}$ of PBS containing $5 \mu \mathrm{g} / \mathrm{ml}$ PI and viable cells were determined using a flow cytometer (Becton-Dickinson, San Jose, CA, USA) as previously described $(13,14)$. Cells were then stained with PI/RNase
Staining Buffer (BD Biosciences Pharmingen, San Diego, CA, USA) and analyzed for cell cycle distribution including sub-G1 phase using a FACScan flow cytometer (Becton-Dickinson) as previously described $(22,23)$.

Annexin V-FITC/PI flow cytometric analysis for apoptotic cell death. Following treatment with TPL for $48 \mathrm{~h}$, the A375. $\mathrm{S} 2$ cells $\left(2 \times 10^{5}\right)$ were harvested and washed twice with icecold PBS. The Annexin V-FITC apoptosis detection kit (Molecular Probes, Eugene, OR, USA) was used for staining the phosphatidylserine on the outside of the apoptotic cells. Briefly, $20 \mu \mathrm{l}$ aliquots of Annexin V-FITC and $40 \mu \mathrm{l}$ PI buffer were added to $400 \mu \mathrm{l}$ of Annexin V-FITC binding buffer and after each treatment the cells were incubated at room temperature for $15 \mathrm{~min}$ in the dark. All samples were analyzed with fluorescence-activated cell sorting (FACS; Becton-Dickinson) as described previously $(24,25)$.

Determination of ROS production, intracellular $\mathrm{Ca}^{2+}$ release and $\Delta \Psi_{m}$. A375.S2 cells $\left(2 \times 10^{5}\right.$ cells/well $)$ were placed onto 12-well plates and treated with $20 \mathrm{nM}$ TPL for 0,12 , 24 and $48 \mathrm{~h}$ for ROS, $\mathrm{Ca}^{2+}$ and $\Delta \Psi m$ measurements. Cells were harvested after each treatment then re-suspended in $500 \mu \mathrm{l}$ of DCFH-DA $(10 \mu \mathrm{M})$ for $\mathrm{ROS}\left(\mathrm{H}_{2} \mathrm{O}_{2}\right)$ determination, re-suspended in $500 \mu \mathrm{l}$ of Fluo-3/AM $(2.5 \mu \mathrm{g} / \mathrm{ml})$ for intracellular $\mathrm{Ca}^{2+}$ concentrations and suspended in $500 \mu \mathrm{l}$ of $\mathrm{DiOC}_{6}$ ( $4 \mu \mathrm{mol} / 1$ ) for $\Delta \Psi_{m}$ followed by incubation at $37^{\circ} \mathrm{C}$ for $30 \mathrm{~min}$. The cells were then analyzed by flow cytometry as described previously $(24,25)$.

Caspase-3, -8 and -9 activity assay. The A375.S2 cells ( $2 \times 10^{5}$ cells/well) were maintained in 12-well plates for $24 \mathrm{~h}$ and then 0 and $20 \mathrm{nM}$ of TPL were individually added to the wells followed by incubation for $0,12,24$ and $48 \mathrm{~h}$. All cells were trypsinized, collected and centrifuged and washed twice with PBS. All samples were re-suspended in $50 \mu \mathrm{l}$ of $10 \mu \mathrm{M}$ substrate solution (CaspaLux 8- $\mathrm{L}_{1} \mathrm{D}_{2}$ for caspase-8, CaspaLux9- $\mathrm{M}_{1} \mathrm{D}_{2}$ for caspase- 9 and PhiPhiLux- $\mathrm{G}_{1} \mathrm{D}_{1}$ for caspase-3) before being incubated at $37^{\circ} \mathrm{C}$ for $60 \mathrm{~min}$. All samples were washed with PBS and analyzed by flow cytometry as described previously (26).

Western blot analysis for the determination of apoptosis-associated proteins. The A375.S2 cells ( $1 \times 10^{6}$ cells/well) in 6-well plates were treated with $20 \mathrm{nM}$ of TPL and then incubated for $0,12,24$ and $48 \mathrm{~h}$ for the determination of proteins associated with cell cycle arrest and apoptosis. Cells were harvested and washed with cold PBS and then lysed with ice-cold lysis buffer containing $50 \mathrm{mM}$ HEPES (pH 7.7), $150 \mathrm{mM} \mathrm{NaCl}, 1 \mathrm{mM}$ EDTA, 2.5 mM EGTA, 1 mM DTT, 0.1\% Tween-20, 10\% (v/v) glycerol, $1 \mathrm{mM} \mathrm{NaF}$, protease inhibitor cocktail (Roche Diagnostics GmbH, Mannheim, Germany) and phosphatase inhibitor cocktail (Sigma Chemical Co.). The total proteins from each sample were quantified using the Bio-Rad method. Each sample (50 $\mu \mathrm{g}$ protein) was resolved over 12\% sodium dodecylsulfate polyacrylamide gel electrophoresis (SDS-PAGE) and transferred onto nitrocellulose membranes (Millipore, Billerica, MA, USA). The blot was then soaked in blocking buffer (5\% non-fat dry milk/0.05\% Tween-20 in 20 mM TBS at $\mathrm{pH}$ 7.6) at room temperature for $1 \mathrm{~h}$ and then incubated with 

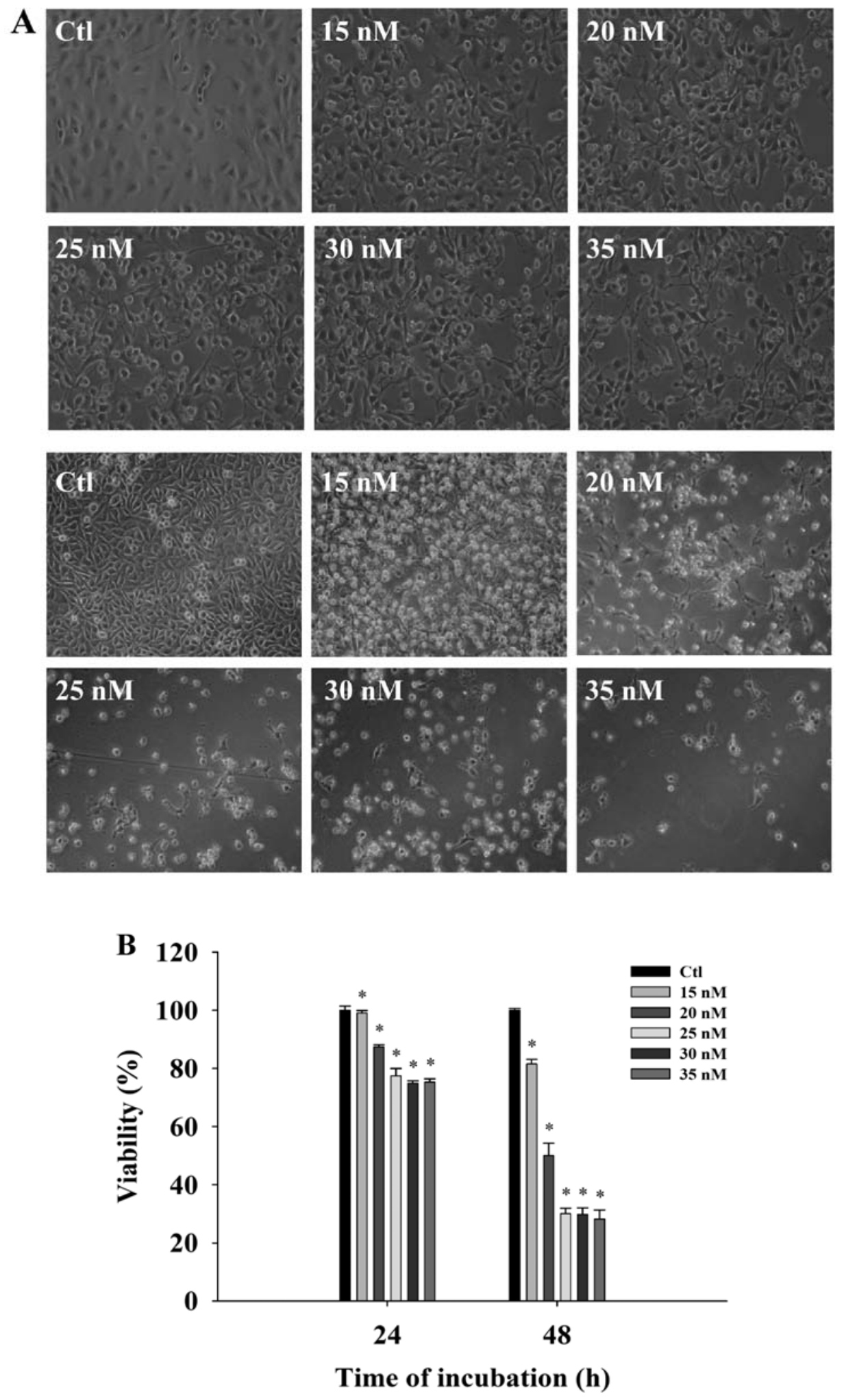

Figure 1. Triptolide induced cell morphological changes and decreased the percentage of viable A375.S2 cells. Cells were plated onto MEM + 10\% FBS with various concentrations of triptolide for 24 and $48 \mathrm{~h}$. (A) The morphological changes were examined and photographed under a phase-contrast microscope, and (B) the total percentages of viable cells was determined by flow cytometry as described in Materials and methods. Each point is the means \pm SD of three experiments. " $\mathrm{P}<0.05$, significant difference compared to the control.

individual primary monoclonal antibodies in blocking buffer at $4^{\circ} \mathrm{C}$ overnight, followed by secondary antibody horseradish peroxidase conjugate and detection by chemiluminescence and autoradiography using X-ray film as described previously (26).
To ensure equal protein loading, each membrane was stripped and re-probed with anti- $\beta$-actin antibody $(24,26)$. Dilutions of primary antibodies were 1:1,000 [antibodies specific for caspase-9, $-8,-3$, cytochrome $c$, apoptosis-inducing factor (AIF), 
A
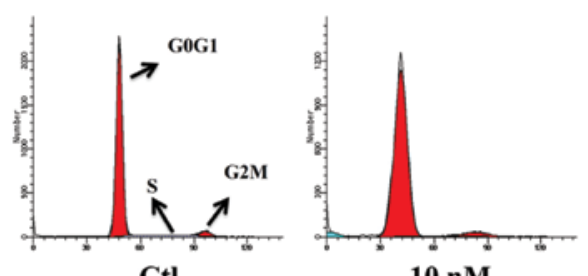

Ctl

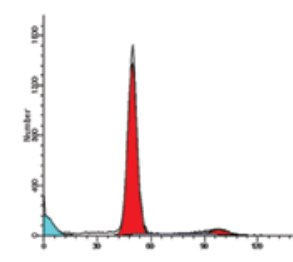

$15 \mathrm{nM}$

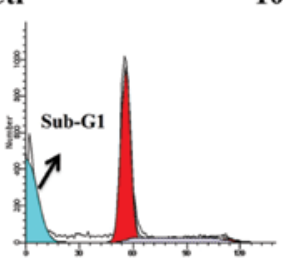

$20 \mathrm{nM}$

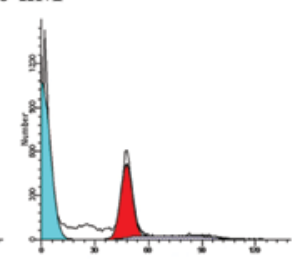

$25 \mathrm{nM}$

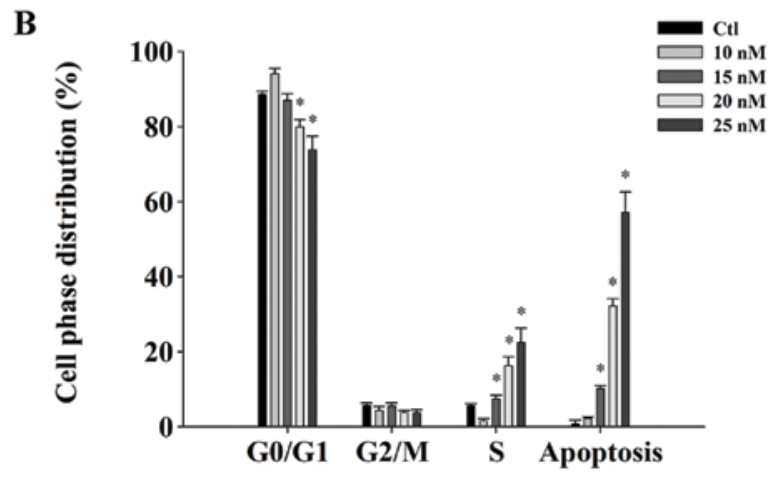

Figure 2. Triptolide induced cell cycle arrest at the sub-G1 phase in A375. $\mathrm{S} 2$ cells. Cells were treated with various concentrations of triptolide for $48-\mathrm{h}$ and then harvested for cell cycle and sub-G1 analysis by flow cytometry as described in Materials and methods. (A) Representative profiles of the cell cycle. (B) Perrcentage of cells in each phase of the cell cycle. Each point is the means $\pm \mathrm{SD}$ of three experiments. ${ }^{*} \mathrm{P}<0.05$, significant difference compared to the control.

endonuclease G (Endo G), Bcl-x, Bax, Fas, FasL and glucoseregulated protein (GRP)78].

Statistical analysis. The quantitative data are presented as the means \pm SD. Statistical differences between the TPL-treated and control samples were calculated using the Student's t-test. A value of $\mathrm{P}<0.05$ was considered to indicate a statistically significant difference. The results are representative of at least three independent experiments $(24,26)$.

\section{Results}

TPL induces cell morphological changes and decreases the percentage of viable A375.S2 cells. In order to confirm the biological effects of TPL, the A375.S2 cells were treated with various concentrations of TPL for 24 and $48 \mathrm{~h}$, and cell morphological changes and the percentage of viable cells were determined. The results are shown in Fig. 1, indicating that TPL induced morphological changes (Fig. 1A) and decreased the percentage of viable cells in a concentration-dependent manner (Fig. 1B).

TPL induces $S$ phase arrest in A375.S2 cells. To investigate the inhibitory effect of TPL on cell growth, we investigated
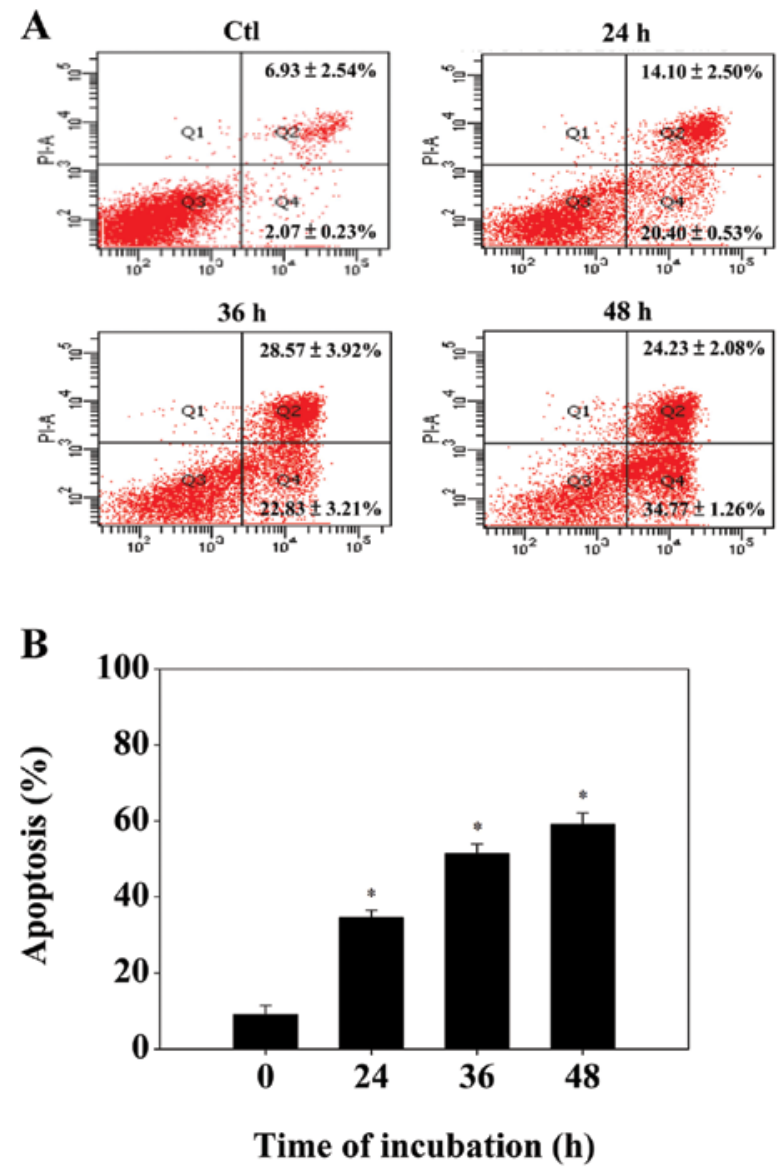

Figure 3. Triptolide induced apoptosis in A375.S2 cells. Cells were incubated with various concentrations of triptolide for 12, 24 and $48 \mathrm{~h}$. Apoptotic cells were determined by Annexin V/PI staining and analyzed by flow cytometry as described in Materials and methods. (A) Representative profiles of Annexin V/ PI staining. (B) Percentage of apoptotic cells. Each experiment was performed in triple sets. ${ }^{*} \mathrm{P}<0.05$, significant difference compared to the control $(\mathrm{Ctl})$.

the cell cycle distribution in A375.S2 cells by flow cytometry and the results are shown in Fig. 2. The number of cells in the G1, S, G2/M and sub-G1 phase of the cell cycle showed that the A375.S2 cells accumulated in the $S$ and Sub-G1 phases following exposure to TPL, whereas the G1 cell population was decreased in a concentration-dependent manner. Collectively, these observations suggest that TPL causes $S$ phase arrest and induces apoptosis in A375.S2 cells.

TPL induces apoptosis in A375.S2 cells. To further confirm that TPL induces apoptosis in A375.S2 cells, the cells were exposed to $20 \mathrm{nM}$ of TPL for different periods of time and then apoptosis was analyzed. The results are shown in Fig. 3. The results indicated that TPL induced apoptosis in timedependent manner.

TPL promotes $R O S$ production, intracellular $\mathrm{Ca}^{2+}$ release and decreases $\Delta \Psi m$ in A375.S2 cells. To further investigate the role of ROS, $\mathrm{Ca}^{2+}$ and the loss of $\Delta \Psi m$ in TPL-induced apoptosis in A375.S2 cells, the cells were treated with $20 \mathrm{nM}$ of TPL for different periods of time. The harvested cells were analyzed for ROS and $\mathrm{Ca}^{2+}$ production and the loss of $\Delta \Psi m$. The results are shown in Fig. 4A-C. The results indicated that TPL promoted the production of ROS (Fig. 4A) and $\mathrm{Ca}^{2+}$ 

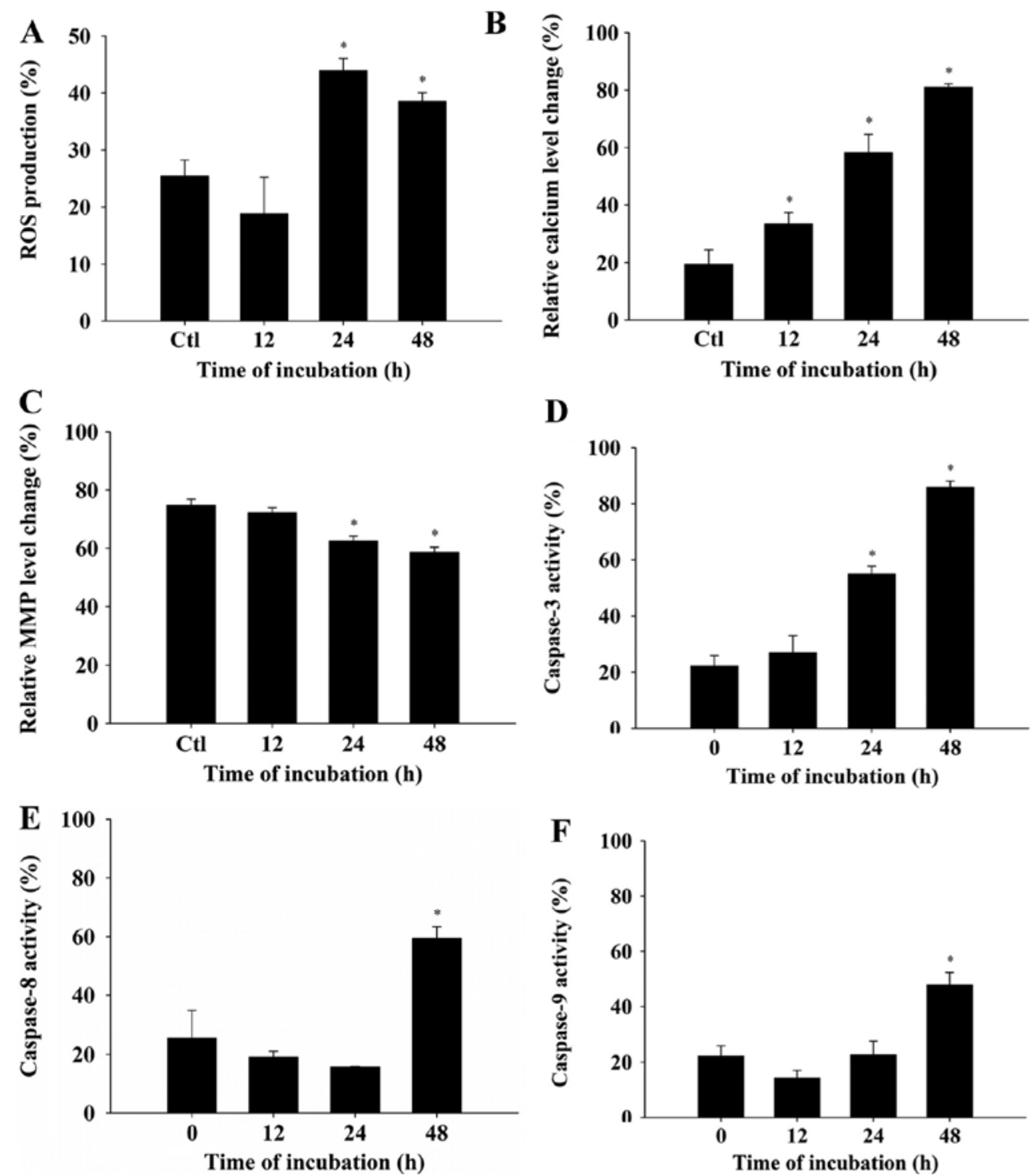

Figure 4. Triptolide affected the levels of reactive oxygen species (ROS), intracellular $\mathrm{Ca}^{2+}$ production, mitochondrial membrane potential $(\Delta \Psi \mathrm{m})$ and increased caspase-3, -8 and -9 activity in A375.S2 cells. Cells were incubated with $20 \mathrm{nM}$ triptolide for different periodes of time, prior to staining with (A) 2,7-dichlorodihydrofluorescein diacetate (DCFH-DA) for determination of ROS levels, (B) Fluo-3/AM for determination of intracellular $\mathrm{Ca}^{2+}$ levels and (C) DiOC ${ }_{6}$ for $\Delta \Psi m$ determination. The cells were harvested and analyzed for the activities of (D) caspase-3, (E) caspase- 8 and (F) caspase- 9 followed by flow cytometry as described in Materials and methods. Each experiment was performed in triple sets. Data represent the means \pm SEM of three independent experiments. ${ }^{*} \mathrm{P}<0.05$, significant difference compared to the control.

(Fig. 4B) but $\Delta \Psi m$ (Fig. 4C) in the A375.S2 cells. These effects occurred in a time-dependent manner. These results show that TPL-induced apoptosis in A375.S2 cells involves the production of ROS and $\mathrm{Ca}^{2+}$ and the decrease in $\Delta \Psi m$.

TPL promotes the activation of caspase-3, -8 and -9 in A375. $S 2$ cells. In order to investigate whether caspase-3, -8 and -9 are involved in TPL-induced apoptosis, the enzymatic activity of caspases was detected using three foluorogenic peptide substrates (CaspaLux 8- $\mathrm{L}_{1} \mathrm{D}_{2}$ for caspase-8, CaspaLux9- $\mathrm{M}_{1} \mathrm{D}_{2}$ for caspase-9 and PhiPhiLux- $\mathrm{G}_{1} \mathrm{D}_{1}$ for caspase-3). The results are shown in Fig. 4C-E, indicating that TPL induced a rapid increase in caspase-3, -8 and -9 activity. The co-treatment of A375.S2 cells with pan-caspase inhibitor led to a significant decrease in the activity of caspase- $3,-8$ and -9 . These findings show that TPL-induced apoptosis in A375.S2 cells involves caspase activation.
TPL affects the cell cycle and apoptosis-associated proteins in A375.S2 cells. In order to investigate whether the TPL-induced $\mathrm{S}$ phase arrest and apoptosis involves apoptosis-associated proteins in A375.S2 cells, the cells were treated with $20 \mathrm{nM}$ TPL for $0,12,24$ and $48 \mathrm{~h}$ and then examined by western blot analysis. The results are shown in Fig. 5A-D, indicating that TPL increased the levels of p21 and p27 but inhibited those of CDK2, cyclin E and CDC25A (Fig. 5A), leading to $\mathrm{S}$ phase arrest. TPL promoted the expression of GADD153, GRP78, caspase-4, IRE and calpain 1 (Fig. 5E), indicating that TPL induced apoptosis through ER stress. Furthermore, TPL promoted the expression of caspase-8, Fas and FasL (Fig. 5B and D), Bax and Bid, but inhibited the levels of Bcl-2 (Fig. 5C). However, it increased the levels of. cytochrome $c$, caspase-9 and -3, AIF and Endo G (Fig. 5B). These findings show that TPL induces apoptosis via the caspase- and mitochondrial-dependent pathway in A375.S2 cells. 
A

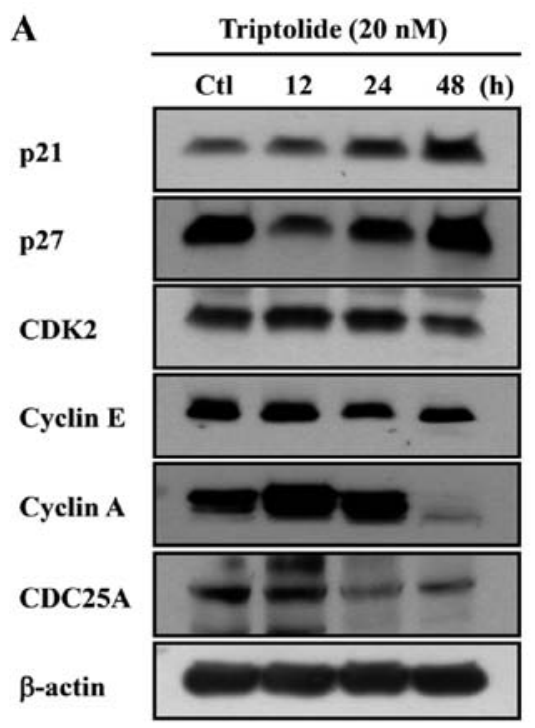

C

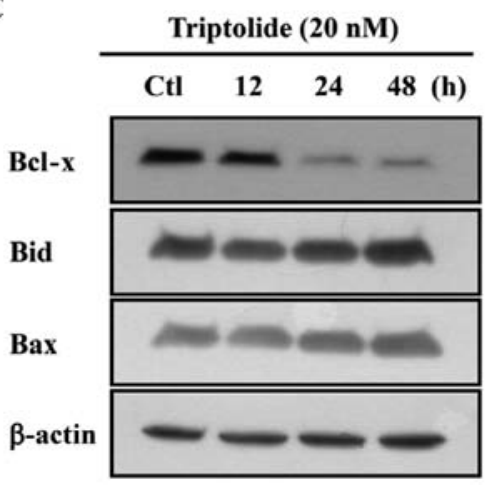

$\mathbf{E}$

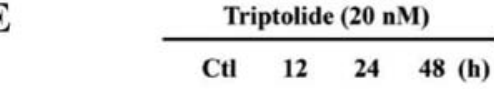

B

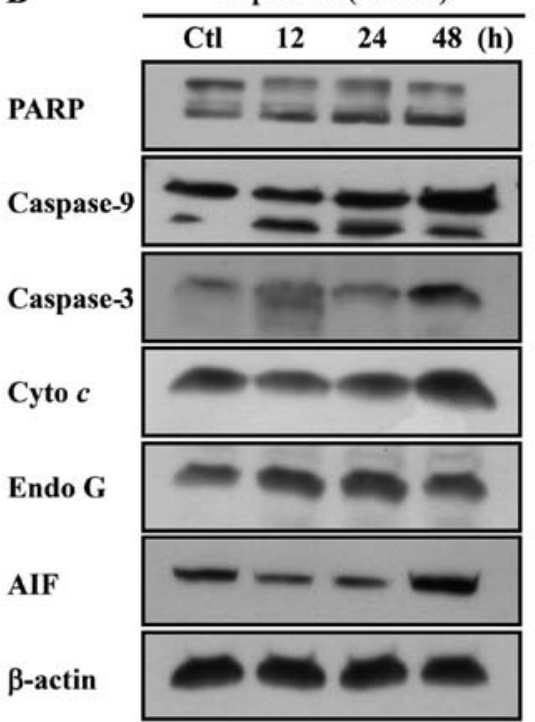

D

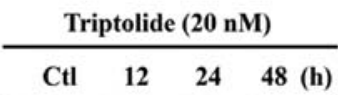

Caspase-8

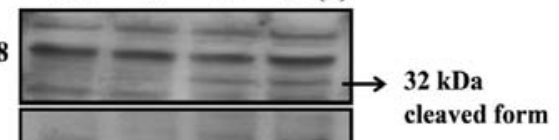

Fas-L

Fas

$\beta$-actin

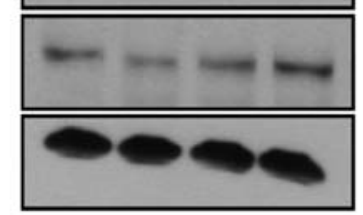

F

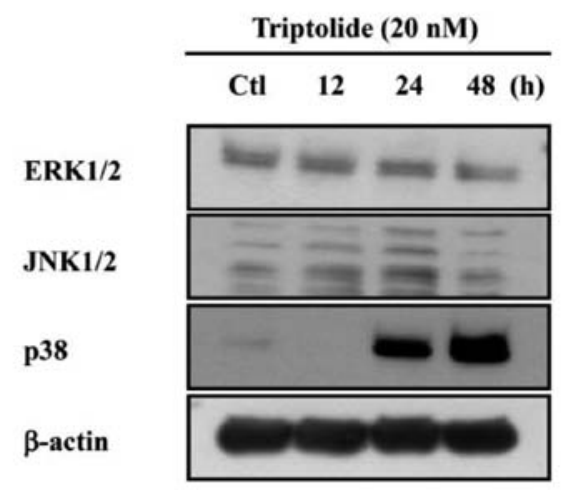

Figure 5. Triptolide affected the cell cycle and apoptosis-associated proteins in A375.S2 cells. A total of 1x106 A375.S2 cells/ml cells in 6-well plate were treated with $20 \mathrm{nM}$ triptolide for $0,12,24$ and $48 \mathrm{~h}$. Cells were harvested and apoptosis-associated proteins were measured by western blot analysis. The protein levels of (A) p21, p27, CDK2, cyclin E, cyclin A and CDC25A, (B) cytochrome $c$, caspase-9 and -3, AIF and Endo G, (C) Bax, Bad, Bcl-x, (D) caspase-8, Fas and FasL, (E) GADD153, GRP78, caspase-4, IRE $\alpha$ and $\beta$, calpain 1 and (F) ERK1/2, JNK1/2 and p38 were examined using SDS-PAGE gel electrophoresis and western blot analysis as described in Materials and methods.

\section{Discussion}

Previous studies have shown that melanomas are resistant to conventional chemotherapy and metastasize to the brain, lung, liver and skin $(27,28)$. Attention has been drawn to alternative options for the treatment and prevention of cancer, including treatments derived from herbs. Natural products for the treatment of cancer include antioxidants and cancer preventative agents, or cancer therapeutic drugs $(29,30)$. TPL is one of the major active compounds in Tripterygium wilfordii 


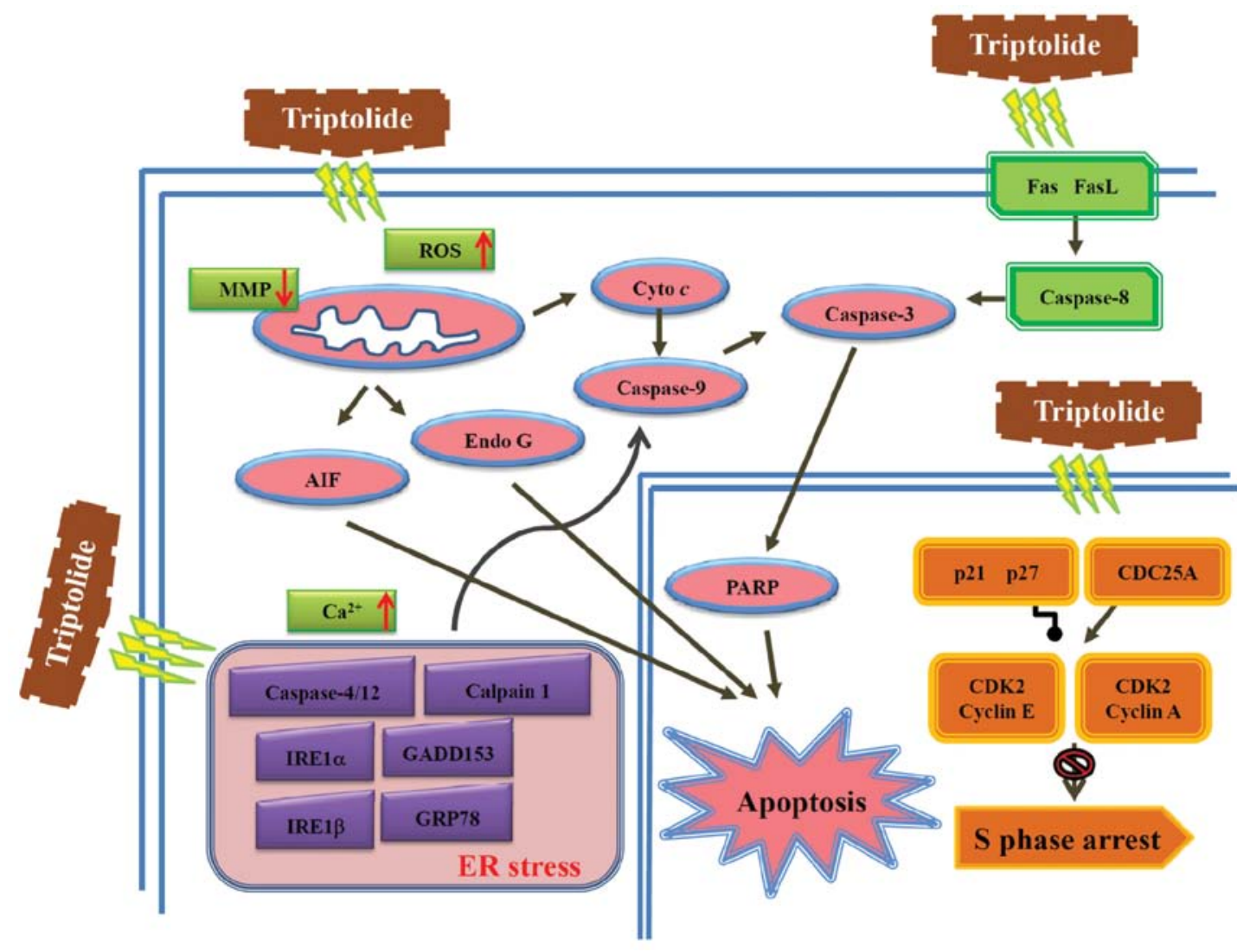

Figure 6. The proposed signaling pathways of triptolide-induced cell cycle arrest and apoptosis in A375.S2 human melanoma cells.

Hook F. extract, with potent anti-inflammatory and anticancer activity $(12,31,32)$. In this study, we investigated Chinese herbal TPL for its effects against human melanoma skin cancer cells in vitro. Our results from flow cytometric analysis showed that TPL significantly inhibited cell growth, inducing $\mathrm{S}$ phase arrest and apoptosis in A375.S2 human melanoma cells (Figs. 1 and 2).

To our knowledge, our findings are the first to show that TPL induces cytotoxic effects in human melanoma skin cancer cells. These effects include cell morphological changes and the decrease in the percentage of viable cells, as well as the induction of $\mathrm{S}$ phase arrest and apoptosis (Figs. 1-3). TPL also promoted caspase-8, -9 and -3 activity (Fig. 4D-F). We also used pan-caspase inhibitor, which led to an increase in the percentage of viable cells compared to the cells treated with TPL alone. These results are in agreement with those from previous studies, demonstrating that caspase- 8 and -9 can be activated by TPL in pancreatic cancer cells $(15,33,34)$. It is well known that the activation of caspase- 8 and -9 involves two different apoptotic pathways $(22,35)$. Caspase- 8 involves the extrinsic pathway which is triggered by Fas and FasL and caspase- 9 involves the intrinsic pathway which is triggered by the increase in the ratio of $\mathrm{Bax} / \mathrm{Bcl}-2$, leading to mitochondrial dysfunction through the caspase-dependent pathway or directly leading to the release of AIF and Endo G from the mitochondria (mitochondrial-dependent pathway; also termed caspase-dependent pathway) (22,35). It has been reported that the TPL-induced apoptosis is related to its ability to reduce DcR3 expression and increase FasL expression $(36,37)$. In this study, we found TPL induced caspase-3, -8 and -9 activation (Fig. 4D-F) and increased the expression of Fas and FasL (Fig. 5D). These results further support the notion that TPL is a potent activator of caspases in A375.S2 cells.

Our results also showed that TPL inhibited the phosphorylation of ERK1/2 and JNK1/2 (Fig. 5F); however, it did not alter the level of phosphorylation of MEK1 and MEK1/2. These results are in agreement with those from previous studies, showing that TPL inhibits the phosphorylation of ERK1/2 and affects ERK1/2 activation directly (17,38). Our findings also showed that TPL promoted the expression of p21 and p27 in A375.S2 cells. It has been reported that p21 is a well-characterized CDK inhibitor; high levels of p21 can inhibit cyclin D1 expression, resulting in the decline of $\mathrm{pRb}$ phosphorylation $(39,40)$. In this study, we did not observe any significant changes in the A375.S2 cells following exposure to TPL. However, we did observe the inhibition of cyclin A and CDC25A in the A375.S2 cells following exposure to TPL, which may be the mechanism of action behind the TPL-induced $S$ phase arrest (Fig. 5A).

In conclusion, the results from the present study demonstrated that the exposure of A375.S2 cells to TPL led to S phase arrest and the induction of apoptosis (Fig. 6). TPL induced $\mathrm{S}$ phase arrest via the promotion of p21 and p27 and the inhibition of cyclin A and CDC25A expression. TPL induced the apoptosis of A375.S2 cells via Fas and FasL, leading to the activation of caspase-dependent and -independent signaling pathways. Apoptosis was also induced, in part, through the ER stress pathways. 


\section{Acknowledgements}

This study was supported by CMU-101-Asia-04 from the China Medical University, Taichung, Taiwan, R.O.C.

\section{References}

1. Freedman DM, Dosemeci M and McGlynn K: Sunlight and mortality from breast, ovarian, colon, prostate, and nonmelanoma skin cancer: a composite death certificate based case-control study. Occup Environ Med 59: 257-262, 2002.

2. Rodriguez-Villanueva $\mathbf{J}$ and McDonnell TJ: Induction of apoptotic cell death in non-melanoma skin cancer by interferonalpha. Int J Cancer 61: 110-114, 1995.

3. Cromwell KD, Ross MI, Xing Y, et al: Variability in melanoma post-treatment surveillance practices by country and physician specialty: a systematic review. Melanoma Res 22: 376-385, 2012.

4. Ascierto PA, Gogas HJ, Grob JJ, et al: Adjuvant interferon alfa in malignant melanoma: An interdisciplinary and multinationa expert review. Crit Rev Oncol Hematol: Aug 5, 2012 (Epub ahead of print).

5. Chen GG and Lai PB: Role of apoptosis in chemotherapy. Curr Drug Targets 11: 650-651,2010.

6. Guerriero JL, Ditsworth D, Fan Y, Zhao F, Crawford HC and Zong WX: Chemotherapy induces tumor clearance independent of apoptosis. Cancer Res 68: 9595-9600, 2008

7. Oberoi-Khanuja TK, Karreman C, Larisch S, Rapp UR and Rajalingam K: Role of melanoma inhibitor of apoptosis (ML-IAP) protein, a member of the baculoviral IAP repeat (BIR) domain family, in the regulation of C-RAF kinase and cell migration. J Biol Chem 287: 28445-28455, 2012.

8. Günther C, Neumann H, Neurath MF and Becker C: Apoptosis, necrosis and necroptosis: cell death regulation in the intestinal epithelium. Gut: Jun 27, 2012 (Epub ahead of print).

9. Liu Y, Chen Y, Lamb JR and Tam PK: Triptolide, a component of Chinese herbal medicine, modulates the functional phenotype of dendritic cells. Transplantation 84: 1517-1526, 2007.

10. Leuenroth SJ, Okuhara D, Shotwell JD, et al: Triptolide is a traditional Chinese medicine-derived inhibitor of polycystic kidney disease. Proc Natl Acad Sci USA 104: 4389-4394, 2007.

11. Tan BJ, Tan BH and Chiu GN: Effect of triptolide on focal adhesion kinase and survival in MCF-7 breast cancer cells. Oncol Rep 26: 1315-1321, 2011.

12. Messina ME Jr and Halaby R: Does triptolide induce lysosomal-mediated apoptosis in human breast cancer cells? Med Hypotheses 77: 91-93, 2011.

13. Lee KY, Park JS, Jee YK and Rosen GD: Triptolide sensitizes lung cancer cells to TNF-related apoptosis-inducing ligand (TRAIL)-induced apoptosis by inhibition of NF-kappaB activation. Exp Mol Med 34: 462-468, 2002.

14. Zhu W, Li J, Wu S, et al: Triptolide cooperates with Cisplatin to induce apoptosis in gemcitabine-resistant pancreatic cancer. Pancreas 41: 1029-1038, 2012.

15. Wang W, Li X, Sun W, et al: Triptolide triggers the apoptosis of pancreatic cancer cells via the downregulation of Decoy receptor 3 expression. J Cancer Res Clin Oncol 138: 1597-1605, 2012.

16. Liu Y, Song F, Wu WK, et al: Triptolide inhibits colon cancer cell proliferation and induces cleavage and translocation of 14-3-3 epsilon. Cell Biochem Funct 30: 271-278, 2012.

17. Liu J, Shen M, Yue Z, et al: Triptolide inhibits colon-rectal cancer cells proliferation by induction of G1 phase arrest through upregulation of p21. Phytomedicine 19: 756-762, 2012.

18. Shi X, Jin Y, Cheng C, et al: Triptolide inhibits Bcr-Abl transcription and induces apoptosis in STI571-resistant chronic myelogenous leukemia cells harboring T315I mutation. Clin Cancer Res 15: 1686-1697, 2009

19. Pigneux A, Mahon FX, Uhalde M, et al: Triptolide cooperates with chemotherapy to induce apoptosis in acute myeloid leukemia cells. Exp Hematol 36: 1648-1659, 2008

20. Yao GH, Luan JF, Ye D, et al: Effects of triptolide on proliferation and apoptosis of Jurkat cell line in acute T lymphocytic leukemia. Zhongguo Shi Yan Xue Ye Xue Za Zhi 16: 506-509, 2008 (In Chinese).
21. Wu PP, Liu KC, Huang WW, et al: Triptolide induces apoptosis in human adrenal cancer NCI-H295 cells through a mitochondrialdependent pathway. Oncol Rep 25: 551-557, 2011.

22. Hsiao YP, Yu CS, Yu CC, et al: Triggering apoptotic death of human malignant melanoma a375.s 2 cells by bufalin: involvement of caspase cascade-dependent and independent mitochondrial signaling pathways. Evid Based Complement Alternat Med 2012: 591241,2012

23. Huang SH, Wu LW, Huang AC, et al: Benzyl isothiocyanate (BITC) induces G2/M phase arrest and apoptosis in human melanoma A375.S2 cells through reactive oxygen species (ROS) and both mitochondria-dependent and death receptor-mediated multiple signaling pathways. J Agric Food Chem 60: 665-675, 2012.

24. Lu CC, Yang JS, Chiang JH, et al: Novel quinazolinone MJ-29 triggers endoplasmic reticulum stress and intrinsic apoptosis in murine leukemia WEHI-3 cells and inhibits leukemic mice. PLoS One 7: e36831, 2012.

25. Huang WW, Yang JS, Lin MW, et al: Cucurbitacin E induces $\mathrm{G}(2) / \mathrm{M}$ phase arrest through STAT3/p53/p21 signaling and provokes apoptosis via Fas/CD95 and mitochondria-dependent pathways in human bladder cancer T24 cells. Evid Based Complement Alternat Med 2012: 952762, 2012.

26. Yang JS, Hour MJ, Huang WW, Lin KL, Kuo SC and Chung JG: MJ-29 inhibits tubulin polymerization, induces mitotic arrest, and triggers apoptosis via cyclin-dependent kinase 1-mediated $\mathrm{Bcl}-2$ phosphorylation in human leukemia U937 cells. J Pharmacol Exp Ther 334: 477-488, 2010.

27. Nowak M, Strzelczyk A, Reif PS, et al: Minocycline as potent anticonvulsant in a patient with astrocytoma and drug resistant epilepsy. Seizure 21: 227-228, 2012.

28. Fidler IJ: The role of the organ microenvironment in brain metastasis. Semin Cancer Biol 21: 107-112, 2011.

29. Eichhorn T and Efferth T: P-glycoprotein and its inhibition in tumors by phytochemicals derived from Chinese herbs. J Ethnopharmacol 141: 557-570, 2012.

30. Schneekloth JS Jr and Crews CM: Natural product inhibitors of the ubiquitin-proteasome pathway. Curr Drug Targets 12: 1581-1594, 2011.

31. Zhao H, Yang Z, Wang X, et al: Triptolide inhibits ovarian cancer cells invasion by repression of MMP7, MMP19 and upregulation of E-cadherin. Exp Mol Med: Aug 20, 2012 (Epub ahead of print).

32. Wang Y, Lu JJ, He L and Yu Q: Triptolide (TPL) inhibits global transcription by inducing proteasome-dependent degradation of RNA polymerase II (Pol II). PLoS One 6: e23993, 2011.

33. Yang SW, Wang W, Xie XY, Zhu WP and Li FQ: In vitro synergistic cytotoxic effect of triptolide combined with hydroxycamptothecin on pancreatic cancer cells. Am J Chin Med 39: 121-134, 2011.

34. Mujumdar N, Mackenzie TN, Dudeja V, et al: Triptolide induces cell death in pancreatic cancer cells by apoptotic and autophagic pathways. Gastroenterology 139: 598-608, 2010.

35. Chernigovskaia EV, Iamova LA, Atochin D, Huang P and Glazova MV: Interaction of neuronal NOS and catecholamines in regulation of expression of proteins of apoptosis by vasopressinergic hypothalamic neurons. Zh Evol Biokhim Fiziol 47: 232-238, 2011 (In Russian)

36. Chen YW, Lin GJ, Chia WT, Lin CK, Chuang YP and Sytwu HK: Triptolide exerts anti-tumor effect on oral cancer and KB cells in vitro and in vivo. Oral Oncol 45: 562-568, 2009.

37. Yang M, Huang J, Pan HZ and Jin J: Triptolide overcomes dexamethasone resistance and enhanced PS-341-induced apoptosis via PI3k/Akt/NF- $\kappa \mathrm{B}$ pathways in human multiple myeloma cells. Int J Mol Med 22: 489-496, 2008.

38. Li W, Liu Y, Li XX, et al: MAPKs are not involved in triptolideinduced cell growth inhibition and apoptosis in prostate cancer cell lines with different p53 status. Planta Med 77: 27-31, 2011.

39. Ferrandiz N, Caraballo JM, Garcia-Gutierrez L, et al: p21 as a transcriptional co-repressor of S-phase and mitotic control genes. PLoS One 7: e37759, 2012.

40. Mauro M, Rego MA, Boisvert RA, et al: $\mathrm{p} 21$ promotes error-free replication-coupled DNA double-strand break repair. Nucleic Acids Res 40: 8348-8360, 2012. 